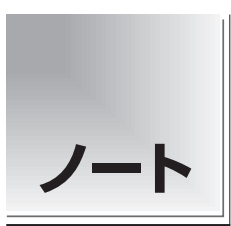

論文受付

2011 年 6 月 21 日

論文受理

2011 年 12 月 27 日

Code No. 811

\section{オペレータコンソールに表示される線量值の評価 : 位置決め画像から撮影線量を決定している CT 装置において}

\author{
1 川崎医科大学附属病院中央放射線部 \\ 2 川崎医療短期大学放射線技術科
}

佐内弘恭 ${ }^{1}$ 友光達志 ${ }^{2}$ 池長弘幸 ${ }^{1}$ 末森慎治 ${ }^{1} \quad$ 柳元真一 ${ }^{1}$

\section{緒 言}

Computed tomography $(\mathrm{CT})$ 装置の発展に伴って CT の適応範囲が拡大したことによって，医療被ばくの増加 が懸念されている。特に，2004 年にLancetに掲載され た医療被ばくに関する論文1によって，CTによる被ばく 線量が注目されるようになった。

CTの撮影線量の低減については, 画像取得技術の 進歩と並行して進められてきた。撮影線量の低減技術 の中で最も重要なものの一つとして CT 用自動露出機構 (CT automatic exposure control; CT-AEC) が挙げられ る. CT-AEC は, 位置決め画像や直前の投影デー夕を 基に被写体構造を解析し, 管電流を連続的に変化させ
ることによって，目標とする画質(画像ノイズ)を保ちな がら撮影線量を最適化する技術である ${ }^{2 \sim 5)}$. CT 撮影を 実施する際には，撮影担当者が検査内容に合わせた画 質を選択すると, それによってオペレータコンソール (コンソール)に volume CT dose index(CTDIvol)と dose length product(DLP)が表示され，被検者に応じた画質 の最適化と撮影線量の確認が可能となる.

しかし，コンソールに表示される線量值(コンソール 表示值)について評価した報告は少なく，管電流值を一 定に設定した場合の報告6,7)が散見されるのみである. そこで, 位置決め画像のデー夕から適切な撮影線量を 決定する方式の CT-AECを採用している 2 種類の CT

\title{
Assessment of the Exposure Dose Value Displayed on Operator Console in a Computed Tomography System Deciding Exposure Dose from Positioning Image
}

\author{
Hiroyasu Sanai, ${ }^{*}$ Tatsushi Tomomitsu, ${ }^{2}$ Hiroyuki Ikenaga, ${ }^{1}$ Shinji Suemori, ${ }^{1}$ and Shinichi Yanagimoto \\ ${ }^{1}$ Department of Radiological Technology, Kawasaki Medical School Hospital \\ ${ }^{2}$ Department of Radiological Technology, Kawasaki College of Allied Health Professions
}

Received June 21, 2011; Revision accepted December 27, 2011

Code No. 811

\section{Summary}

The aim of this study was to assess the exposure dose value (DLP) displayed on the operator console in a computed tomography system with automatic exposure control (CT-AEC) which decides the exposure dose from a positioning image. We measured exposure dose with two kinds of CT systems and evaluated the error of the displayed DLP value on the operator console against the measured DLP value. The assessment was performed in three sites: head and neck, upper chest, and lower abdomen. As a result, the errors of displayed value with CT-AEC against the error without CT-AEC in system A (4.09\%) were significantly different on two assessment sites (head and neck: $-4.02 \%$, upper chest: $6.60 \%$ ). There is no significant difference on the third assessment site (lower abdomen: 0.06\%). On the other hand, those values in system B (8.38\%) were almost similar with no significant differences (head and neck: $-1.12 \%$, upper chest: $-1.85 \%$, lower abdomen: $-0.64 \%$ ). The results show that there were significant differences noted between the errors of displayed value with CT-AEC and without CT-AEC in system A for the head and neck and the upper chest. In conclusion, displayed value with CT-AEC and without CT-AEC were about the same error. However, the possibility that the error depended on a model and the examination site of CT was shown.

Key words: exposure dose, dose length product, computed tomography automatic exposure control

*Proceeding author 


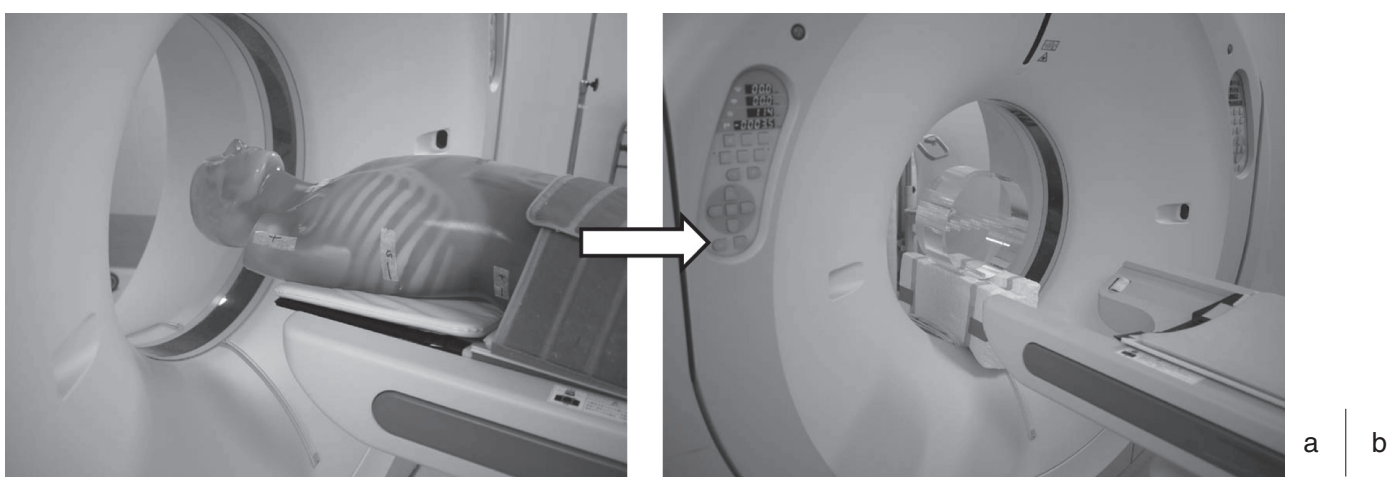

Fig. 1 Experimental alignment for the computed tomography dose index volume (CTDIvol) measurement.

(a) The human phantom was set up on a bed.

(b) The phantom for the CTDIvol measurement was set up in the gantry of CT system.

Table 1 Exposure conditions of CT except tube current and CT-AEC condition

\begin{tabular}{lcc}
\hline \hline & System A & System B \\
\hline Tube voltage $(\mathrm{kV})$ & 120 & 120 \\
Rot time $(\mathrm{s} / \mathrm{rot})$ & 0.5 & 0.5 \\
Scan FOV & Large $(40 \mathrm{~cm} \phi)$ & Large $(50 \mathrm{~cm} \phi)$ \\
Beam width & $32 \mathrm{~mm}(1 \mathrm{~mm} \times 32 \mathrm{DAS})$ & $20 \mathrm{~mm}(1.25 \mathrm{~mm} \times 16 \mathrm{DAS})$ \\
Beam pitch & 0.844 & 0.938 \\
\hline
\end{tabular}

装置を用いて線量測定を行った。そして，測定值に対 するコンソール表示值の誤差から CT-AEC 使用時のコ ンソール表示值を評価したので報告する.

\section{1. 方 法}

\section{1-1 使用機器}

CT 装置は Aquilion64(東芝メディカルシステムズ, system A), LightspeedUltra16(GEヘルスケア, system B) を使用した。両 system ともに位置決め画像のデー夕から 適切な撮影線量を決定する方式の CT-AEC を採用してい る. 線量計には, プローブとして有効電離長 $100 \mathrm{~mm} の$ ペンシル型電離箱(W23342-1251，PTW）を装着した Ramtec1500-B(東洋メディック)を使用した。 ファントム については, CTDI 測定には CTDI 測定用ファントム(直 径 $32 \mathrm{~cm}$, 京都科学) を, 位置決め画像取得時には CT 人体ファントム $(\mathrm{PBU} 41$ ，京都科学)をそれぞれ用いた。

\section{1-2 CTDIvol の測定および DLP の算出}

CT-AEC を使用しない場合の測定は，管電流值を system A では小焦点を使用するために $100 \mathrm{~mA}$, system B では大焦点を使用するために $250 \mathrm{~mA}$ 一定に設定し た，そして，被検者寝台のアタッチメント部分を外して ガントリに直接発泡スチロール製の台を配置し，その上
にCTDI 測定用ファントムを設置して CTDIvol の測定 を実施した(Fig. 1b).

他方，CT-AEC を使用する場合の測定は，まず被験 者寝台上の CT 人体ファントムをガントリ中心に配置し て，外形情報を得るために側面，正面の順に 2 方向の 位置決め画像を取得した，次いで，上記と同様にCTDI 測定用ファントムを設置して CTDIvol の測定を実施し た(Fig. 1).

測定は, system A ではV Volume EC を, system B で は auto $\mathrm{mA}$ と smart $\mathrm{mA}$ を稼働した条件下で測定し た。また，画質条件は，system A では頭頸部と上胸部 は standard deviation $(\mathrm{SD}) 10$ に，下腹部は SD 15 に設定 し, system B では頭頸部は noise index 8.5 に，上胸部 は noise index 18, 下腹部は noise index 15 に設定し た。今回は, CT-AEC 使用時の線量を評価するため に，管電流值が上限值あるいは下限值に達しないよう に部位によって画質条件を変更した，なお，使用する焦 点サイズによって管電流值と CTDIvol の直線性(傾き) が変化する傾向が CT 装置の表示值に見られたため, 画質条件は CT-AEC を使用しない場合の測定と同じ焦 点サイズ(system A は小焦点, system B は大焦点)に設 定した，管電流と CT-AECの画質条件以外の撮影条件 は Table 1 に示すとおりである. 


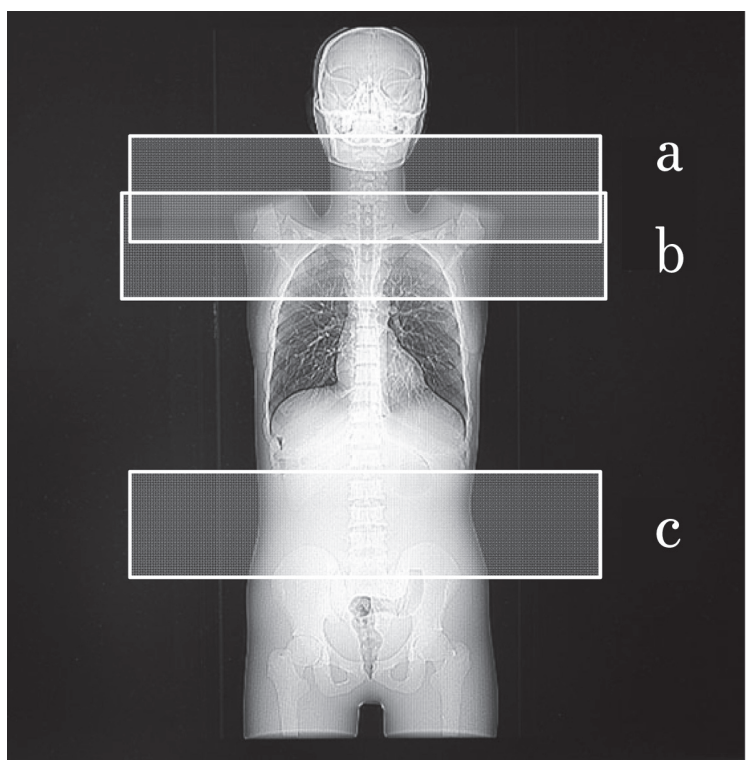

Fig. 2 Measurement site of CTDIvol with CT-AEC.

(a) Head \& neck

(b) Upper chest

(c) Lower abdomen

測定部位は頭頸部，上胸部，下腹部の 3 力所(Fig. 2) とし, 測定方法は医療被ばく測定テキスト ${ }^{8)}$ に則って行 い，実測值は 3 回測定の平均值とした。

そして, 測定したCTDIvolに, 下式で求めた撮影距 離を乗算して DLP(DLP 実測值)を求めた。

Exposure distance $(\mathrm{cm})=\frac{\text { Exposure time }(\mathrm{s})}{\text { Rotation time }(\mathrm{s} / \mathrm{rot})} \times$ Beam width $(\mathrm{cm})$

$\times$ Beam pitch

なお、コンソールに表示される CTDIvol は, system A では撮影範囲における最大管電流值, system B は平均 管電流值を基に計算を行っている，そのため，今回の方 法による評価では, system A に表示される CTDIvol の 誤差が明らかに大きくなるため使用しなかった、コン ソールに表示される DLP(DLP 表示值)は，両システム とも積算線量を用いて算出しているため, 今回はこちら を評価に用いた。

\section{1-3 誤差の算出}

誤差の算出方法は，DLP 実測值を基準として，コン ソールに表示されるDLP 表示值との差を求めた，そし て，それぞれの systemにおいて，CT-AECを使用しな い場合の誤差を基準とし，CT-AECを使用した場合の 誤差について評価を行った。な拉，評価には paired $\mathrm{t}$-test を用い, 有意水準は $5 \%(\mathrm{p}<0.05)$ とした。

\section{1-4 CT-AEC 使用時の管電流值変化}

CT-AEC の使用によって，撮影時の管電流值が大き く変化する。 そして, その変化が表示值と実測值の誤 差に影響を与えると思われるため, CT-AEC 使用時の 撮影における管電流值の変化を把握する必要がある。 今回は，管電流值の変化を, CTDIvol 測定時に撮影し た画像に表示される管電流值で評価した。そして，管 電流值として, 3 回の測定における撮影データから, ス ライスごとに平均管電流值を算出してその值を採用し た。なお，画像に表示される管電流值は， system A で はスライス中心に抢ける前後方向と左右方向の管電流 值の平均值が, system B ではスライスを構成するため に使用したデー夕の平均管電流值がそれぞれ用いられ ている.

\section{2. 結 果}

両 system における DLP 実測值と表示値，ならびに 実測值に対する表示值の誤差を Table 2 に示す.

System A の DLP 表示值は, CT-AECを使用しない場 合の誤差が 4.09\%であり，これを基準とすると，頭頸部 では $4.02 \%$ の有意な減少が, 上胸部は $6.60 \%$ の有意な 増加 $(\mathrm{p}<0.001)$ がそれぞれ認められた。しかし，下腹部 では有意差は認められなかった。

他方, system B の DLP 表示值は, CT-AECを使用し ない場合の誤差がそれぞれ $8.38 \%$ であった。また，

CT-AEC 使用時の不使用時との誤差は，すべての部位で $2 \%$ 未満の減少を示し, 有意な差は認められなかった。

次に, CT-AEC 使用時のスライスごと (5 mm 間隔)の 管電流值変化を Fig. 3 に示す。管電流值の変化は，頭 頸部では両 system において管電流值が下降した後, 上 昇する同様の傾向であった。ただし， system B の方が 最大管電流值と最小管電流值の差は大きかった。 上胸 部では, system A では $65 \mathrm{~mm}$ の位置をピークとした緩 やかな山型の形状を示し, system B では $15 \mathrm{~mm}$ 付近を ピークとして急峻な下降を示す形状であり，両者は明ら かに異なる形状であった。下腹部では，両 system とも に $120 \mathrm{~mm}$ 付近まで同様の傾向を示したが, $120 \mathrm{~mm}$ 以降では system B では急激な管電流值の上昇が認め られた。

\section{3. 考 察}

System A のCT-AEC 使用時における DLP 表示值の 誤差は，CT-AECを使用しない場合と比較して，下腹 部は有意な差を認めなかった。それに対して，頭頸部 では有意な減少 $(\mathrm{p}<0.001)$ を, 上胸部では有意な増加 
Table 2 Error of the DLP value between measured value and displayed value

\begin{tabular}{|c|c|c|c|c|c|}
\hline & \multicolumn{2}{|c|}{$\operatorname{DLP}(\mathrm{mGy} \cdot \mathrm{cm})$} & \multirow{2}{*}{$\begin{array}{c}\text { Error }(\%) \\
{[(\mathrm{A}-\mathrm{B}) / \mathrm{B} \times 100]}\end{array}$} & \multirow{2}{*}{$\begin{array}{c}\text { Difference of the error }(\%) \\
\text { (with CT-AEC-without CT-AEC) }\end{array}$} & \multirow{2}{*}{$\mathrm{p}$ value ${ }^{*}$} \\
\hline & Displayed value (A) & Measured value (B) & & & \\
\hline \multicolumn{6}{|l|}{ 1. System A } \\
\hline Without CT-AEC & 146.30 & $140.56 \pm 0.33$ & $4.09 \pm 0.24$ & & \\
\hline \multicolumn{6}{|l|}{ With CT-AEC } \\
\hline Head \& neck & $112.13 \pm 0.58$ & $112.06 \pm 0.94$ & $0.07 \pm 0.36$ & -4.02 & $<0.001$ \\
\hline Upper chest & $141.60 \pm 1.45$ & $127.93 \pm 1.34$ & $10.69 \pm 0.35$ & 6.60 & $<0.001$ \\
\hline Lower abdomen & n $\quad 222.37 \pm 3.18$ & $213.53 \pm 3.97$ & $4.15 \pm 0.46$ & 0.06 & $\mathrm{NS}^{* *}$ \\
\hline \multicolumn{6}{|l|}{ 2. System B } \\
\hline Without CT-AEC & 223.74 & $206.48 \pm 3.13$ & $8.38 \pm 1.65$ & & \\
\hline \multicolumn{6}{|l|}{ With CT-AEC } \\
\hline Head \& neck & $190.08 \pm 6.19$ & $176.40 \pm 3.87$ & $7.26 \pm 1.48$ & -1.12 & NS** \\
\hline Upper chest & $112.16 \pm 5.71$ & $105.29 \pm 5.57$ & $6.53 \pm 0.26$ & -1.85 & NS ** \\
\hline Lower abdomen & n $\quad 164.49 \pm 7.71$ & $153.31 \pm 5.16$ & $7.74 \pm 1.37$ & -0.64 & $\mathrm{NS}^{* *}$ \\
\hline
\end{tabular}

*: versus the error of without CT-AEC

**: not significant
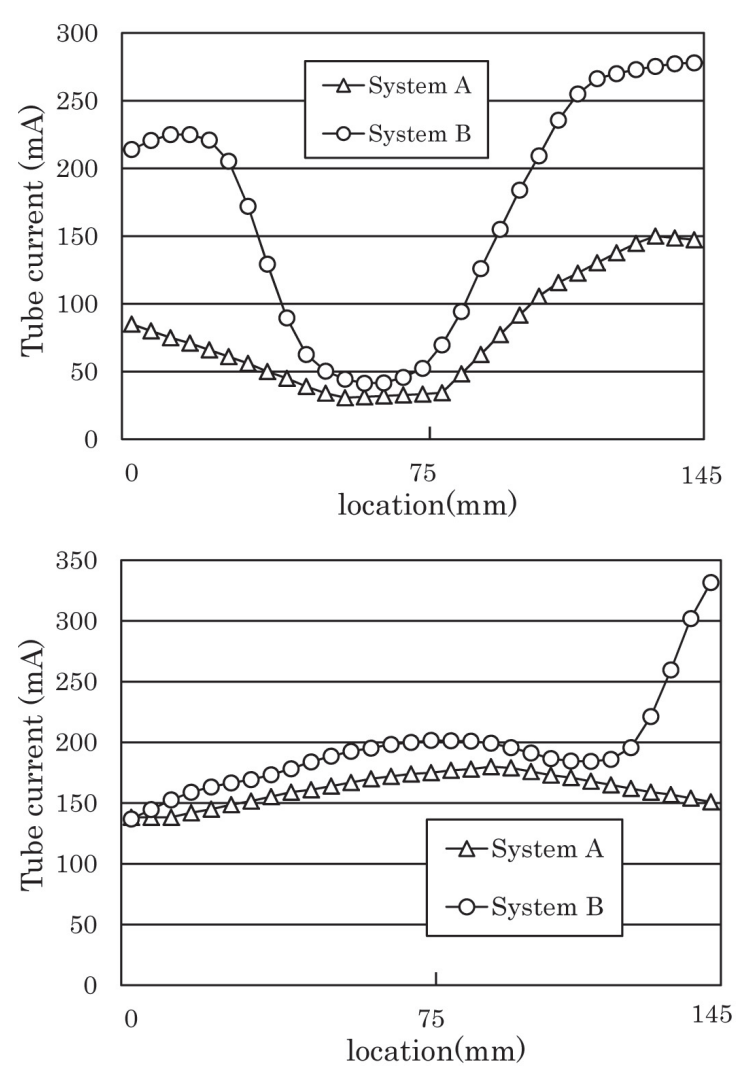

$(\mathrm{p}<0.001)$ が認められ，部位によって異なる結果が示さ れた。これは，管電流の制御もしくは実際に照射される X 線の出力が被写体の形状変化に追従できていないこ とが主な原因と考えられた。下腹部については, 外形 がほぼ一定なため管電流值の変化が他の 2 部位に比べ て直線に近く, CT-AECを使用しない場合との差が最 も少なくなったと思われる。

System B の表示值の誤差は, CT-AECを使用しない
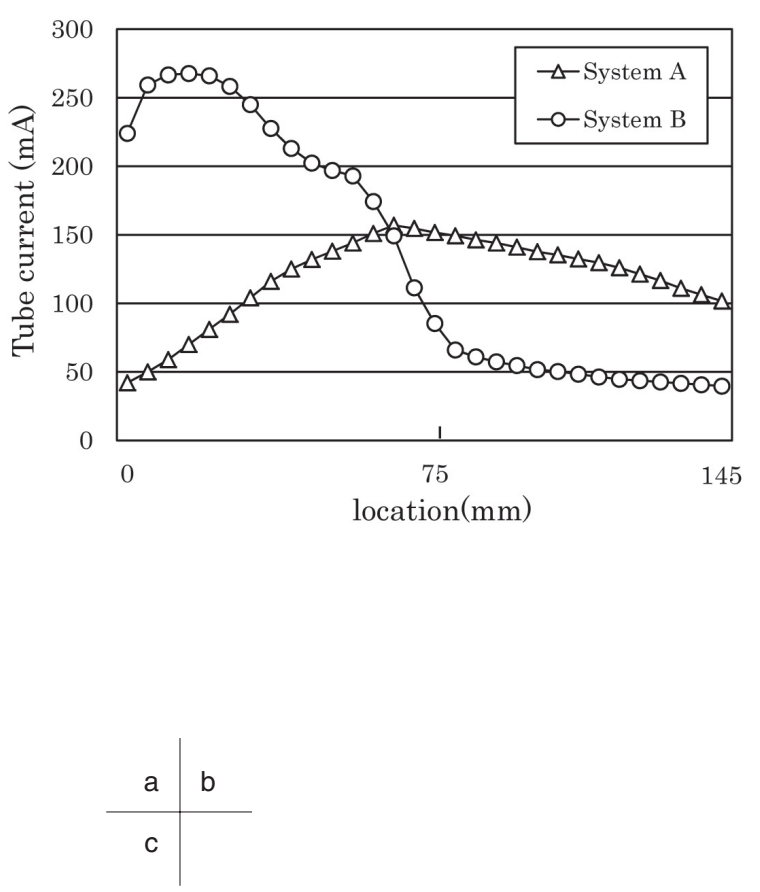

Fig. 3 The tube current changing with CT-AEC.
(a) Head \& neck
(b) Upper chest
(c) Lower abdomen

場合と比較して，すべての部位で $2 \%$ 未満の減少を示 したが，有意差は認められなかった。

両 system のCT-AEC 使用時における，部位間の誤 差の変化に着目すると, system A の方が部位間の差が 大きかった。 これは, 両 system のビーム幅や管電流制 御の違いが関係しているものと考えられた。すなわち， system Aのビーム幅が $3.2 \mathrm{~cm}$ であるのに対し, system

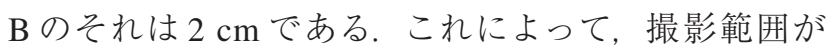


system A では $3.8 \mathrm{~s}$ (約 8 回転)で, systemB では $4.8 \mathrm{~s}$ (約 10 回転)で撮影される。被写体の形状変化に合わせた 管電流の制御は，ビーム幅が小さく，回転数が多い方が 容易であると思われる。 また, Fig. 3 の上胸部や，下腹 部の $135 \mathrm{~mm}$ 付近の管電流変化から, 被写体の形状変 化や X 線吸収量の差が大きい部位での管電流值変化に systemによる制御の差が生じていると思われる。しか し，今回の検討では，二つの systemの撮影条件や画質 条件の設定が異なっており，その影響も含まれていると 考えられるため，更なる検討を加える必要がある。

両 system における CT-AEC 使用時の DLP 表示值と 実測值の誤差は, CT の機種や撮影部位に依存する可 能性が認められた。しかし，DLP表示值は，実測值と の誤差が最大で $11 \%$ 程度であり，常に実測值よりも高 值を示した。臨床において，DLP表示值を用いて線量 評価を行うことは，実際よりも過大評価となるため，安 全側の評価が可能であり，有用であると考えられた。
今回は, 位置決め画像のデータから適切な撮影線量 を決定する方式の CT-AECを採用している CT 装置に おいて検討を行った。しかし，今回行った方法では， X 線管が回転しながら被写体の形状に合わせて管電流 を変調する方式の CT-AECを採用している CT 装置を 評価できない。 今後，使用者側で CT-AEC 使用時の測 定值を評価できる方法を考案することが必要だと思わ れた。

\section{4. 結 語}

今回検討を行った二つの system において, CT-AEC を使用した場合にオペレータコンソールに表示される DLP を評価し，以下の結果が得られた。

1)使用 system や撮影部位にかかわらず，表示值の方が 実測值よりも大きい值を示した。

2)実測值に対する表示值の誤差は, CT-AEC 使用時と 不使用時は，ほぼ同程度であったが，system や部位に よって傾向が異なっていた

\section{参考文献}

1) Berrington de González A, Darby S. Risk of cancer from diagnostic X-rays: estimates for the UK and 14 other countries. Lancet 2004; 363(9406): 345-351.

2) Kalra MK, Maher MM, Toth TL, et al. Techniques and applications of automatic tube current modulation for CT. Radiology 2004; 233(3): 649-657.

3) Mulkens TH, Bellinck P, Baeyaert M, et al. Use of an automatic exposure control mechanism for dose optimization in multi-detector row CT examinations: clinical evaluation. Radiology 2005; 237(1): 213-223.

4) 村松禎久, 池田 秀, 木村春樹, 他. CT 用自動露出機構 (CT-AEC) の性能評価班報告書. 日放技学誌 2005; 61 (8): 1094-1103.

5）村松禎久, 池田 秀, 大沢一彰, 他. CT 用自動露出機構 (CT-AEC) の性能評価班最終報告書. 日放技学誌 2007 ; 63(5): 534-545

6) Hamberg LM, Rhea JT, Hunter GJ, et al. Multi-detector row CT: radiation dose characteristics. Radiology 2003; 226(3): 762-772.

7) Bongartz G, Golding SJ, Jurik AG, et al. European guidelines for multi slice computed tomography; Quality criteria 2004; Appendix A: Dosimetry. http://biophysicssite.com/ $\mathrm{html} / \mathrm{ct}$ _guidelines.html

8）小山修司. X 線 CT の線量測定の実際。放射線医療技術学 叢書 $(25)$ 医療被ばく測定テキス卜，日本放射線技術学会 出 版委員会, 京都, 2006: 44-57.

Fig. 1 CTDIvol 測定の実験配置図
(a) 人体ファントムを寝台上に配置

(b) CTDI 測定用ファントムをガントリ内に設置

Fig. 2 CT-AEC 使用時の CTDIvol の測定部位
(a) 頸部
(b) 胸部
(c) 腹部

Fig. 3 CT-AEC 使用時の管電流值変化
(a) 頭頸部
(b) 胸部
(c) 腹部

Table 1 管電流と CT-AEC 条件以外の撮影条件

Table 2 実測 DLP に対する表示 DLP の誤差 